\title{
Simulation and Web-based learning increases utilization of Bier block for forearm fracture reduction in the pediatric emergency department
}

\author{
Brett Burstein, MDCM, PhD*; Emmanuelle Fauteux-Lamarre, MD*; Adam Cheng, $\mathrm{MD}^{\dagger}$; \\ Dominic Chalut, MD*; Adam Bretholz, MD*
}

\section{ABSTRACT}

Objectives: Bier block (BB) is a safe and effective alternative to procedural sedation for analgesia during forearm fracture reductions, yet remains infrequently used in the pediatric emergency department (PED). No standardized methods of BB training have previously been described. The objective of this study was to determine whether a multimodal instructional course increases comfort with BB and translates to increased use of this technique.

Methods: A novel interdisciplinary simulation and Web-based training course was developed to teach the use of $B B$ for forearm fracture reduction at a tertiary PED. Participants were surveyed pre-/post-training, and at 2 and 6 months regarding their comfort with BB. In parallel, we prospectively assessed the clinical use of BB for children ages 6 to 18 years requiring closed reduction of forearm fractures during the 24-month post-course period.

Results: Course participation included 26 physicians and 12 nurses. Survey response rate was $100 \%$. Course participation increased both comfort $(10 \%$ pre-training v. $89 \%$ post-training, $p<0.001)$ and the willingness to use BB $(51 \%$ pre-training $v$. 95\% post-training, $p<0.001)$, an effect sustained at 6 months post-course $(66 \%$ and $92 \%$, respectively, $p<0.001$ for both). In clinical practice, there were no BBs performed prior to course administration. We observed a consistent and sustained increase in clinical use among the BB-trained physicians, with $37 \%$ of all forearm reductions performed using BB at 24 months post-course completion.

Conclusions: A novel combined simulation and Web-based training course increased comfort and willingness to use BB and was associated with increased use of this technique for forearm fracture reduction in the PED.

\section{RÉSUMÉ}

Objectif: Bloc nerveux de Bier (BB) est une solution de rechange sûre et efficace à la sédation en vue d'une intervention aux fins d'analgésie dans les cas de réduction de fracture de I'avant-bras; pourtant, elle est peu utilisée au service des urgences pédiatriques (SUP). Aucune méthode uniforme de formation sur le BB n'est décrite dans la littérature médicale. L'étude exposée ici visait à déterminer si un cours de formation reposant sur différentes modes augmenterait la facilité du personnel à appliquer cette forme d'anesthésie et se traduirait par une utilisation accrue de la technique.

Méthode: Un nouveau cours de formation multimodale interdisciplinaire a été élaboré dans le but d'enseigner le recours à le BB pour les réductions de fracture de l'avant-bras dans un SUP de soins tertiaires. Les participants ont répondu à un sondage avant et après la formation ainsi que 2 et 6 mois plus tard relativement à leur facilité à appliquer le BB. Parallèlement à le sondage, les auteurs ont procédé à une évaluation prospective de l'application clinique de le BB chez les enfants âgés de 6 à 18 ans qui devaient subir une réduction fermée de fractures de l'avant-bras au cours de la période de 24 mois qui a suivi le cours. Résultats: Ont participé au cours 26 médecins et 12 infirmières. Le taux de réponse à le sondage a atteint $100 \%$. La participation au cours a permis d'accroître la facilité du personnel à appliquer le BB (10\% avant contre [c.] $89 \%$ après; $p<0,001)$ et sa propension à y recourir (51\% avant c. $95 \%$ après; $p<0,001)$, effet toujours présent 6 mois après le cours $(66 \%$ et $92 \%$ respectivement; $p<0,001$ dans les deux cas). Avant celui-ci, on ne recourait pas, en pratique clinique, à le BB mais, 24 mois plus tard, une augmentation constante et soutenue de I'application de la technique a été observée parmi les médecins ayant assisté à la formation; en effet, $37 \%$ des réductions de fracture de l'avant-bras ont été réalisées à l'aide de le BB.

Conclusions: Une nouvelle formule de cours multimodale a permis d'accroître la facilité du personnel à appliquer le BB (10 \% avant c. $89 \%$ avant c. après; $p<0,001$ ) et sa propension à y recourir, en plus d'être associée à une utilisation plus grande de la technique dans les cas de réduction de fracture de I'avant-bras dans les SUP.

Keywords: intravenous regional anesthesia, lidocaine, procedural sedation

From the *Division of Pediatric of Pediatric Emergency Medicine, The Montreal Children's Hospital, McGill University Health Centre, Montreal, OC; and TSection of Emergency Medicine, Department of Pediatrics, Alberta Children's Hospital, University of Calgary, Calgary, AB.

Correspondence to: Adam Bretholz, The Montreal Children's Hospital, 1001 Decarie Boulevard, Montreal, QC H4A 3J1; Email: adambretholzmd $@$ gmail.com 


\section{INTRODUCTION}

Fractures of the distal forearm are among the most common injuries presenting to the pediatric emergency department (PED). Forearm fractures represent nearly $25 \%$ of all childhood fractures, and approximately $19 \%$ of these require a closed reduction. ${ }^{1,2}$ A closed reduction is most often performed in the PED setting with analgesia for manipulation provided using procedural sedation (PS). While generally well tolerated, the agents used for PS can be associated with post-procedural emesis, psychotomimetic recovery reactions, and adverse airway events. ${ }^{3,4}$ Moreover, patients undergoing PS require ongoing post-procedural monitoring until they return to a pre-procedural level of alertness, ${ }^{5}$ prolonging length of stay and increasing associated costs. ${ }^{6}$

Intravenous (IV) regional anesthesia, or Bier block (BB), is a safe and effective alternative to PS for forearm fracture reduction. The procedure consists of isolating the circulation of the affected limb with a pneumatic cuff and infusing lidocaine for rapid and complete anesthesia of the tourniquet-injured extremity. Patients remain awake throughout the procedure, without risk of central nervous system depression and/or respiratory effects. BB requires no pre-procedural fasting or postprocedural observation periods. Consequently, this technique is associated with reduced PED time and resource utilization. ${ }^{6}$ Furthermore, several studies have demonstrated the efficacy of $\mathrm{BB}$ for forearm fracture reduction, with very infrequently reported adverse events. $^{7-10}$ One large Canadian retrospective review of 1816 adult and pediatric BB procedures reported zerofailed reductions, no major adverse events, and a minor adverse event rate of only $0.5 \% .^{10}$

Despite the many advantages offered by the use of BB, it remains an infrequently used technique. In a survey of 44 North American pediatric emergency medicine fellowship program directors, only $19 \%$ of respondents reported that $\mathrm{BB}$ was ever used for forearm fracture reductions at their centres. ${ }^{11}$ The most common reason cited for not using local anesthesia techniques (including BB) was the efficacy of PS, and the authors further suggested decreased physician comfort level as a barrier to more widespread use of this regional technique.

In June 2012, our tertiary PED introduced BB as an analgesic alternative to PS for forearm fracture reductions, becoming the first Canadian PED to successfully implement a BB program. Prior to the implementation of the BB program, we designed and administered a novel simulation and Web-based training course for PED staff, and undertook a survey-based assessment of attitudes regarding BB. In parallel, we prospectively evaluated the clinical use of $\mathrm{BB}$ in the PED following course delivery. We hypothesized that a multimodal training course would increase staff comfort and willingness to use $\mathrm{BB}$, and ultimately lead to increased use of this technique for closed forearm fracture reductions in the PED. The specific objectives of this study were to 1 ) assess PED staff attitudes regarding BB before and following a multimodal training course, and 2) prospectively determine the in vivo clinical uptake of $\mathrm{BB}$ in the PED following course participation.

\section{METHODS}

\section{Study design, setting, and participants}

We designed and administered an interdisciplinary, multimodal BB training course in June 2012, and used a pre-/post-questionnaire study design to survey course participants at four time points: immediately prior to and following course participation, and at 2 and 6 months following course completion. The study population included PED physicians and nurses at The Montreal Children's Hospital, an urban Canadian tertiary pediatric centre serving children defined as $<18$ years of age, with an annual census of over 84,000 visits. Study participants were asked to complete a onepage, paper questionnaire, which was previously piloted for clarity by individuals not included in the study. ${ }^{12}$ The questionnaire consisted of multiple-choice questions designed to assess 1) previous experience with $\mathrm{BB}, 2$ ) comfort with and willingness to use $\mathrm{BB}$, and 3 ) the value added by the $\mathrm{BB}$ training course. Attitudes regarding $\mathrm{BB}$ and the $\mathrm{BB}$ training course were assessed using a 4-point Likert scale. Study participant demographic data were also collected. This study was approved by the Research Ethics Board of the McGill University Health Centre, and informed written consent was obtained from all participants.

\section{Training course design}

The BB training course content was developed in consultation with experts, according to consensus-based guidelines and using best-evidence practice recommendations. ${ }^{13-16}$ Participants completed a pre-course, 
self-directed, Web-based learning module prior to attendance of a complementary simulation-based training session. The online learning component provided an overview of the $\mathrm{BB}$ technique and reviewed potential adverse events using text, illustrations, and video. This online pre-course tutorial was developed to complement the simulation-based sessions in order to maximize participant learning and retention. Following completion of the online pre-course tutorial, subjects participated in a standardized, half-day course with simulation-based training and debriefing, which commenced with a 30-minute, evidence-based didactic session. A checklist outlining the critical steps required to safely perform $\mathrm{BB}$ was developed a priori and was distributed and referenced during the course. Participants were provided a pocket card memory aid outlining the signs, symptoms, and management of lidocaine toxicity. Simulations incorporated standardized patients and both high- and low-fidelity mannequins for a hands-on opportunity to practice the $\mathrm{BB}$ technique, as well as to recognize and respond to potential complications. Scenarios and standardized patient roles were tightly scripted to ensure a consistent educational experience for all learners. ${ }^{17} \mathrm{~A}$ total of four 10-minute simulation scenarios were delivered during the course, all involving forearm fractures following various injuries (simulation curriculum available in Online Supplement 1). Scenario one involved obtaining pre-procedural consent with a 17-year-old patient. Scenario two required the use of distraction techniques and medical management for an anxious 16-year-old patient undergoing BB. Scenario three was a case of an 8-year-old patient with equipment failure and seizure. Scenario four was a case of a 10-year-old patient with a local anesthetic medication error and cardiac arrest. All simulation scenarios used the same automatic tourniquet system for BB that was available to participants in the PED of their clinical practice (A.T.S 3000, Zimmer Inc.). The four simulation facilitators had previous training in the use of $\mathrm{BB}$, as well as prior experience in simulation-based education and debriefing ranging from 2 to 10 years. Debriefing sessions were conducted using a mix of PlusDelta and Advocacy-Inquiry methods of debriefing, ${ }^{18}$ without the use of video review, and limited to a maximum of 10 minutes per debriefing. Two identical, English-language training courses were offered over 2 consecutive days by the same instructors. Following course completion, participants were tracked to record $\mathrm{BB}$ procedures performed for maintenance of competency.

\section{Determination of clinical Bier block utilization}

Beginning in May 2012, prior to BB training course administration, all patients presenting to the PED with displaced forearm fractures were captured daily by a research assistant in a prospectively maintained database for research purposes. ${ }^{19}$ In June 2012, following delivery of the BB training course, our PED implemented $\mathrm{BB}$ for the first time as an alternative to PS for children of 6 to 18 years of age presenting with forearm fractures requiring closed reduction. An interprofessional protocol was developed for the safe use of BB in the PED and was approved by the institutional Clinical Practice Review Committee (protocol available in Online Supplement 2). Patients were not eligible for BB if they presented with one of the following contraindications: lidocaine allergy, seizure disorder, blood dyscrasia, compromised circulation, bilateral forearm fractures, open fracture, or if they were non-verbal. Reductions using $\mathrm{BB}$ were performed by pediatric emergency physicians and offered at the discretion of the treating physician with consideration of patient/family preferences. Patients undergoing either $\mathrm{BB}$ or PS for fracture reduction were identified by the research assistant, and patient identification numbers were used to access the electronic patient charts as well as standardized $\mathrm{BB}$ and sedation monitoring forms. Charts were reviewed by a single investigator (EFL), and data were extracted to determine the number of BBs performed, and the number of physicians using $\mathrm{BB}$ for forearm fracture reductions. We included all closed forearm fracture reductions for children greater than 6 years old and eligible for both BB and PS, performed between June 2012 and June 2014 by all pediatric emergency physicians trained during the preimplementation course.

\section{Statistical analysis}

Categorical variables are expressed as proportions and were analysed by McNemar testing for paired data (GraphPad Prism software, v6.03). A minimum sample size of 5 was calculated to achieve $90 \%$ power for detecting a change from $20 \%$ to $80 \%$ on questionnaire responses. A two-tailed $p$-value $<0.05$ was considered statistically significant. 


\section{RESULTS}

Overall, 38 subjects ( $\mathrm{N}=26$ physicians, 12 nurses) participated in the Web- and simulation-based training course. Demographics of the study participants are shown in Table 1. All participants completed pre- and post-course surveys, and the survey response rate at both 2 and 6 months remained at 100\%.

Participants' pre- and post-training attitudes regarding BB are shown in Figure 1. Prior to the course, 10\% of participants indicated that they felt comfortable (score $\geq 3$ ) performing $\mathrm{BB}$ for fracture reduction, compared to $89 \%(p<0.001)$ at the time of course completion. Comfort with BB reportedly fell to $66 \%$ at 6 months $(p=0.02$ v. post-course), although it remained significantly higher than baseline $(p<0.001)$. Willingness to perform $\mathrm{BB}$ was similarly increased by course participation (score $\geq 3 ; 51 \%$ pre-course v. $95 \%$ post-course, $p<0.001)$ and remained elevated at 6 months $(92 \%, p<0.001)$.

Immediately following the course, all of the participants either agreed (42\%) or strongly agreed (58\%) that the course addressed their learning objectives. At 2 months, $45 \%(17 / 38)$ of participants indicated that they felt a refresher course was necessary. Comparatively at 6 months, $66 \%(25 / 38)$ of respondents favoured a refresher course, with a majority of these participants (14/25) endorsing a semiannual review emphasizing simulation-based learning.

We assessed self-reported experience with BB before and following BB training (Figure 2). To ascertain baseline experience prior to the course, $6 \%$ of participants

\begin{tabular}{lcc|}
\hline \multicolumn{2}{|c|}{ Table 1. Participant demographics } \\
\hline & Physicians & Nurses \\
\hline Total & $26(68 \%)$ & $12(32 \%)$ \\
Male & $14(54 \%)$ & $1(8 \%)$ \\
Female & $12(46 \%)$ & $11(92 \%)$ \\
Age & & \\
$\quad 30$ & $2(8 \%)$ & $1(8 \%)$ \\
$31-40$ & $12(46 \%)$ & $5(42 \%)$ \\
$41-50$ & $11(42 \%)$ & $3(25 \%)$ \\
$\geq 51$ & $1(4 \%)$ & $3(25 \%)$ \\
Years in practice & & $2(17 \%)$ \\
$\leq 5$ & $5(24 \%)$ & $2(17 \%)$ \\
$6-10$ & $3(14 \%)$ & $2(17 \%)$ \\
$11-15$ & $9(43 \%)$ & $2(17 \%)$ \\
$16-20$ & $3(14 \%)$ & $4(33 \%)$ \\
$\geq 21$ & $1(5 \%)$ & \\
\hline
\end{tabular}

reported having previously performed $\mathrm{BB}$ in a PED setting other than in our institution. Respondents reported a significant increase in their clinical experience with $\mathrm{BB}$ at 2 months $(37 \%, p=0.02)$ and at 6 months ( $53 \%, p<0.001$ v. pre-course; $p=0.04$ v. 2 months).

To assess the clinical uptake of $\mathrm{BB}$ by preimplementation course-trained physicians, we quantified the clinical use of $\mathrm{BB}$ for fracture reductions in the 24-month period following course delivery (Figure 3). Prior to the training course and $\mathrm{BB}$ implementation in the PED, no BB had been performed at our centre. In the period immediately following course completion, there was a sustained increase in the use of $\mathrm{BB}$, with 79 $\mathrm{BB}$ reductions performed at 24 months by physicians in the study population. Similarly, BB-assisted forearm reductions were performed by an increasingly diverse number of these physicians, with $50 \%(13 / 26)$ of physicians using $\mathrm{BB}$ at 24 months, $46 \%$ (6/13) of whom

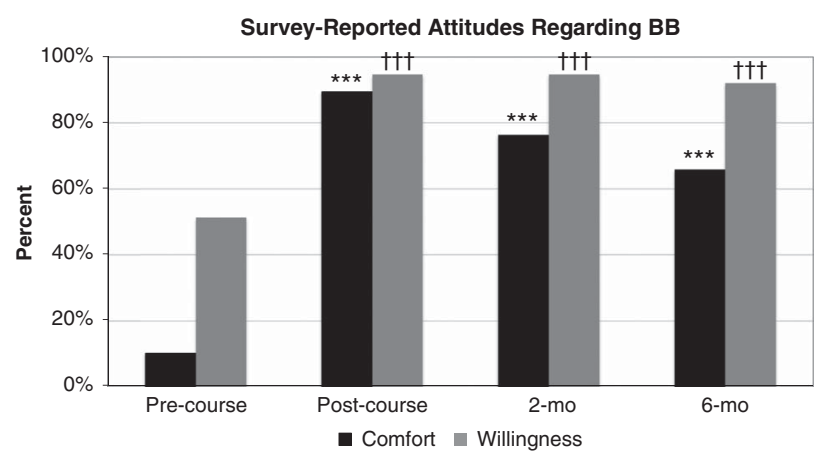

Figure 1. Responses from course participants during pre-course, post-course, 2 and 6 months' post-training regarding comfort with (black bars) and willingness to perform (grey bars) Bier blocks; ${ }^{* *} p<0.001$ v. pre-course comfort, ${ }^{++\dagger} p<0.001 \mathrm{v}$. pre-course willingness.

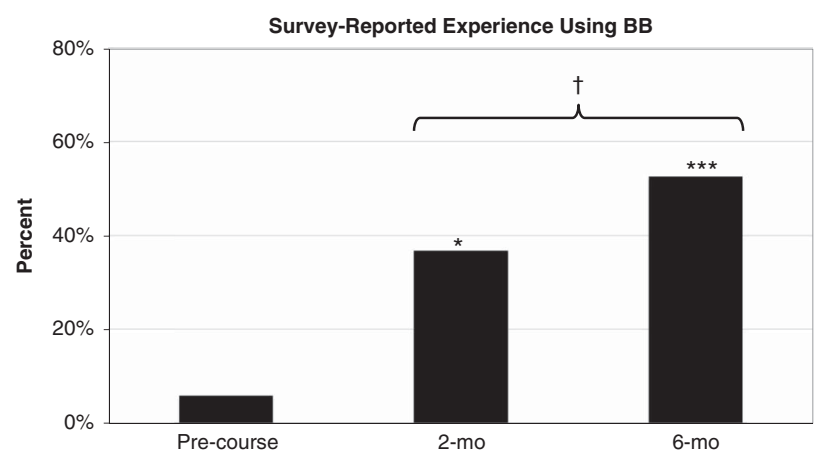

Figure 2. Self-reported responses from course participants pre-course, 2 and 6 months' post-training regarding experience with Bier block; ${ }^{*} p<0.05$ and ${ }^{* *} p<0.001 \mathrm{v}$. pre-course, ${ }^{\dagger} p<0.05$ v. 2 months. 


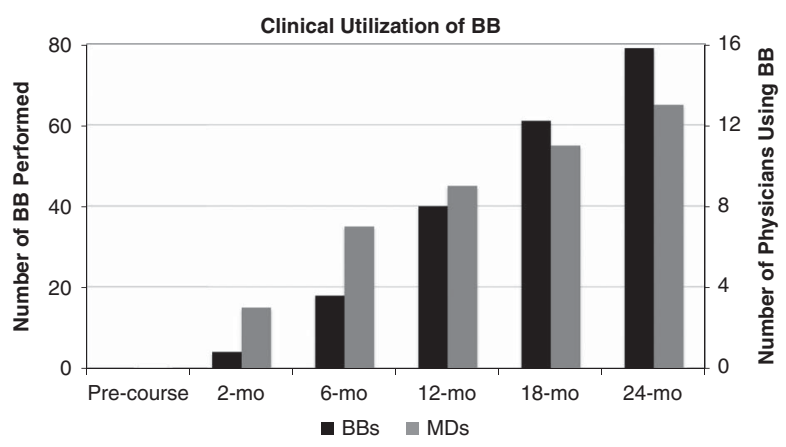

Figure 3. Absolute number of Bier blocks (black bars, left axis) and course-trained PED physicians (grey bars, right axis) performing Bier blocks at intervals following training course delivery.

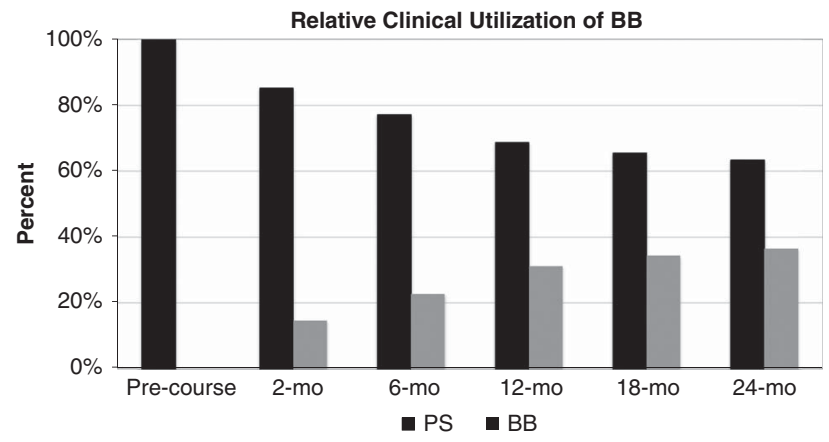

Figure 4. Relative use over time of Bier block (grey bars) and procedural sedation (black bars) for forearm fracture reductions by course-trained PED physicians.

performed $\geq 5 \mathrm{BB}$ by this time. Relative use of $\mathrm{BB}$ in comparison to PS over time is depicted in Figure 4. At 24 months, $37 \%$ of all forearm reductions performed by course-trained physicians used BB (79 BB v. 137 PS).

\section{DISCUSSION}

For the present study, we have designed and administered an interdisciplinary, simulation, and Web-based training course to instruct novice users the technique of $\mathrm{BB}$ for pediatric forearm fracture reductions. Findings demonstrate that the multimodal training course was an effective method for increasing PED staff comfort with, and willingness to use BB for forearm fracture reductions. Moreover, completion of the training course was associated with increased use of $\mathrm{BB}$ in clinical practice, despite low participant comfort and experience with $\mathrm{BB}$ prior to training.

$\mathrm{BB}$ for closed reduction of pediatric forearm fractures has been well described in the literature but remains infrequently used in the PED. ${ }^{11}$ Although the efficacy of PS for pediatric fracture reductions is well established, side effects of sedating agents and the considerable resource utilization associated with $\mathrm{PS}$ make $\mathrm{BB}$ an attractive alternative. There are several theoretical barriers that have thus far potentially limited a more widespread adoption of BB. For example, perceived difficulty placing an IV in an injured extremity might bias against the use of $\mathrm{BB}$ in children; however, this occurred in only 3 of 470 children ages 2 to 19 years in one large case series. ${ }^{7}$ The theoretical lack of muscle relaxation that is thought to facilitate fracture reduction with PS does not appear to compromise reduction success when using BB. $^{7-10}$ Pain that may be associated with the highpressure cuff can be minimized by the use of now readily available dual bladder tourniquet systems, which also provide an increased safety margin to reduce the theoretical risk of lidocaine toxicity. ${ }^{20}$ A systematic review of studies from 1950 to 2007 identified just eight major adverse events among pediatric patients receiving $\mathrm{BB}$, all of which resulted from toxic dosing of local anesthetics and/or unreliable tourniquets; the review highlighted the low incidence of complications and concluded that BB is a safe anesthetic technique. ${ }^{21}$

Despite the advantages offered by the use of BB, staff comfort level remains an important obstacle to more widespread uptake of this technique. Our multimodal training course was developed to increase PED staff comfort with $\mathrm{BB}$ and support the safe implementation of a BB program. The course was designed to maximize participant learning, and we elected to incorporate both simulation and Web-based learning modalities. There is significant literature supporting the use of both computer-assisted and simulation-based education to facilitate the acquisition of procedural skills. ${ }^{22,23}$ A meta-analysis by Lam-Antoniades et al. reviewed 15 studies evaluating education interventions and found that multicomponent interventions were effective at changing health-care professionals' practice patterns and improving their knowledge. ${ }^{24}$ White et al. have demonstrated that a combination of didactic, video, and simulation-based training can augment resident confidence and knowledge for pediatric lumbar puncture procedures. ${ }^{25}$ To our knowledge, this is the first description of a training course to teach the use of $\mathrm{BB}$ for fracture reduction. Participants in our study unanimously indicated that the multimodal training course addressed their learning objectives. It is not possible from our study design, however, to compare this multimodal training, in particular, to another style 
of training, or to determine the added incremental value of either online or simulation-based training alone.

We found that $37 \%$ of all eligible reductions at 24 months were performed using BB by half of the course-trained physicians. Additionally, at 6 months, nearly all participants in our study remained willing to use $\mathrm{BB}$ but reported a moderate yet significant attrition in comfort with BB. Several factors can influence physician comfort and use of $\mathrm{BB}$, including clinical opportunity, patient/family preferences, and department logistics. It is also reasonable to hypothesize that both the number of physicians not using $\mathrm{BB}$ and the reported decline in comfort could relate to a decline in skill retention over time. Skill retention is a well-recognized concern in procedural skill training, and decline of physician knowledge and performance following initial simulation-based training are well described. ${ }^{26,27}$ Several studies have emphasized the importance of refresher courses to maintain critical skill competency. ${ }^{28,29}$ The question of refresher frequency and timing is likely to vary, depending on the psychomotor complexity of the skill being learned as well as how routinely that skill is revisited by an individual in clinical practice. The majority of participants in our study population were in favour of a refresher course at 6 months following course completion. It is possible that refresher course administration would have attenuated the decline in comfort and increased the number of physicians using $\mathrm{BB}$ at 24 months. It remains to be determined the appropriate interval for refresher courses to maintain greater comfort with $\mathrm{BB}$ in the PED.

Several limitations of the present study are inherent to the pre-post study design. Our training course was administered concurrently with the implementation of $\mathrm{BB}$ at our centre, such that it is not possible to isolate effects that result solely from training course delivery. Importantly, our study cohort began with minimal baseline comfort and experience using $\mathrm{BB}$, and we have attempted to determine the extent to which course participation altered participant attitudes towards BB by conducting surveys both immediately before and following course completion. Despite utilization of BB by half of the study physicians for more than a third of all forearm fracture reductions, our survey did not specifically explore the reasons why some physicians were not using BB post-course. Because all study participants completed pre-post surveys, the study cohort had no true control for the training intervention. Findings from this study can be generalized only among novice
BB users. It is of note, however, that a survey of 44 North American pediatric emergency medicine fellowship program directors reported that $\mathrm{BB}$ was seldom used at their centres. ${ }^{11}$ Reported comfort with BB decreased among our study population by 6 months. It is not possible to know what factors specifically account for this attrition, although it is plausible that the temporal distance from the training intervention plays an important role and could be mitigated by refresher courses, as suggested by survey results. We have attempted to mitigate recall bias of participant selfreported experience with $\mathrm{BB}$ by prospectively evaluating the clinical uptake of this technique in the PED following course delivery. We found that the experience reported by participants was corroborated by the sustained parallel increase in both the documented number of BB procedures and the diversity of physicians using this technique at 6 months and beyond. Importantly, the multimodal training course offered has not been externally validated. However, to our knowledge, no other $\mathrm{BB}$ training course has been described previously, and we have used consensus-based guidelines and best-evidence practice recommendations to guide course content. ${ }^{13-16}$ Finally, our study did not assess patient-centered and orthopedic quality measures in the post-implementation period. Although these outcomes are beyond the scope of the current study, they remain an important area of future research.

\section{CONCLUSIONS}

We have described a novel multimodal training course, which increased participant comfort with BB for forearm fracture reduction and was associated with an increased use of this technique in clinical practice. At present, BB is not routinely employed for closed fracture reduction in the PED setting. Course administration achieved the goal of increasing knowledge of this technique and promoting conditions conducive to change in clinical practice. The course design allowed skill acquisition without patient risk, and with the benefit of repeated trials in a safe learning environment. It is our recommendation and hope that this novel training course be adapted to implement the BB at other institutions to support the safe adoption of an effective alternative to PS for forearm fracture reductions. Future work should be directed at assessing orthopedic and patient-centered outcomes following BB-assisted fracture reductions. 
Acknowledgements: The authors wish to thank Rami Rezk, Gabrielle Allard, Elise Mok, and Albert Ho for technical assistance, as well as the McGill University's Steinberg Centre for Simulation and Interactive Learning and the Whistler Health Care Centre's staff and leadership.

Competing interests: None declared.

\section{SUPPLEMENTARY MATERIAL}

To view supplementary material for this article, please visit https://doi.org/10.1017/cem.2016.392

\section{REFERENCES}

1. Landin LA. Fracture patterns in children. Analysis of 8,682 fractures with special reference to incidence, etiology and secular changes in a Swedish urban population 1950-1979. Acta Orthop Scand Suppl 1983;202:1-109.

2. Kramhoft M, Bodtker S. Epidemiology of distal forearm fractures in Danish children. Acta Ortbop Scand 1988;59(5):557-9.

3. Green SM, Roback MG, Krauss B, et al. Predictors of airway and respiratory adverse events with ketamine sedation in the emergency department: an individual-patient data meta-analysis of 8,282 children. Ann Emerg Med 2009;54(2): 158-68, e151-4.

4. Green SM, Roback MG, Krauss B, et al. Predictors of emesis and recovery agitation with emergency department ketamine sedation: an individual-patient data meta-analysis of 8,282 children. Ann Emerg Med 2009;54(2):171-80, e171-4.

5. Evered LM. Procedural sedation and analgesia for paediatric patients in the emergency department. Paediatr Child Health 2003;8(8):503-7.

6. Aarons CE, Fernandez MD, Willsey M, et al. Bier block regional anesthesia and casting for forearm fractures: safety in the pediatric emergency department setting. 7 Pediatr Orthop 2014;34(1):45-9.

7. Blasier RD, White R. Intravenous regional anesthesia for management of children's extremity fractures in the emergency department. Pediatr Emerg Care 1996;12(6):404-6.

8. Bolte RG, Stevens PM, Scott SM, et al. Mini-dose Bier block intravenous regional anesthesia in the emergency department treatment of pediatric upper-extremity injuries. 7 Pediatr Orthop 1994;14(4):534-7.

9. Olney BW, Lugg PC, Turner PL, et al. Outpatient treatment of upper extremity injuries in childhood using intravenous regional anaesthesia. $\mathcal{F}$ Pediatr Orthop 1988;8(5):576-9.

10. Mohr B. Safety and effectiveness of intravenous regional anesthesia (Bier block) for outpatient management of forearm trauma. CFEM 2006;8(4):247-50.

11. Constantine E, Steele DW, Eberson C, et al. The use of local anesthetic techniques for closed forearm fracture reduction in children: a survey of academic pediatric emergency departments. Pediatr Emerg Care 2007;23(4):209-11.

12. Bretholz A, Graham J, Cheng A, et al. Development and evaluation of a Web-based, standardized patient, and simulation course to teach the Bier block technique to pediatric emergency department staff. Abstract presented at the 11th Annual International Meeting on Simulation in Healthcare (New Orleans, LA). Simul Healthc 2010;5(6):383.

13. Kam PC, Kavanagh R, Yoong FF. The arterial tourniquet: pathophysiological consequences and anaesthetic implications. Anaesthesia 2001;56(6):534-45.

14. Kennedy RM, Luhmann JD, Luhmann SJ. Emergency department management of pain and anxiety related to orthopedic fracture care: a guide to analgesic techniques and procedural sedation in children. Paediatr Drugs 2004; 6(1):11-31.

15. Intravenous regional anesthesia. In Roberts JR, Hedges JR (eds.). Clinical procedures in emergency medicine, 5th ed. Philadelphia, PA: Elsevier Health Sciences; 2010: 535-9.

16. Association of periOperative Registered Nurses. Recommended practices for the use of the pneumatic tourniquet in the perioperative practice setting. AORN 7 2007;86(4):640-55.

17. Cheng A, Auerbach M, Hunt EA, et al. Designing and conducting simulation-based research. Pediatrics 2014; 133(6):1091-101.

18. Cheng A, Eppich W, Grant V, et al. Debriefing for technology-enhanced simulation: a systematic review and meta-analysis. Med Educ 2014;48(7):657-66.

19. Dubrovsky AS, Kempinska A, Bank I, et al. Accuracy of ultrasonography for determining successful realignment of pediatric forearm fractures. Ann Emerg Med 2015;65(3):260-5.

20. Henderson CL, Warriner CB, McEwen JA, et al. A North American survey of intravenous regional anesthesia. Anesth Analg 1997;85(4):858-63.

21. Guay J. Adverse events associated with intravenous regional anesthesia (Bier block): a systematic review of complications. 7 Clin Anesth 2009;21(8):585-94.

22. Ricks C, Ratnapalan S, Jain S, et al. Evaluating computerassisted learning for common pediatric emergency procedures. Pediatr Emerg Care 2008;24(5):284-6.

23. Sawyer T, White M, Zaveri $\mathrm{P}$, et al. Learn, see, practice, prove, do, maintain: an evidence-based pedagogical framework for procedural skill training in medicine. Acad Med 2015;90(8):1025-33

24. Lam-Antoniades M, Ratnapalan S, Tait G. Electronic continuing education in the health professions: an update on evidence from RCTs. 7 Contin Educ Health Prof 2009;29(1): 44-51.

25. White ML, Jones R, Zinkan L, et al. Transfer of simulated lumbar puncture training to the clinical setting. Pediatr Emerg Care 2012;28(10):1009-12.

26. Semeraro F, Signore L, Cerchiari EL. Retention of CPR performance in anaesthetists. Resuscitation 2006;68(1):101-8.

27. Chamberlain D, Smith A, Woollard M, et al. Trials of teaching methods in basic life support (3): comparison of simulated CPR performance after first training and at 6 months, with a note on the value of re-training. Resuscitation 2002;53(2):179-87.

28. Niles D, Sutton RM, Donoghue A, et al. "Rolling Refreshers": a novel approach to maintain CPR psychomotor skill competence. Resuscitation 2009;80(8):909-12.

29. Nishiyama C, Iwami T, Murakami Y, et al. Effectiveness of simplified 15-min refresher BLS training program: a randomized controlled trial. Resuscitation 2015;90:56-60. 